\title{
A Unified Model of Oil/Water Two-Phase Flow through the Complex Pipeline
}

\author{
Qingchun Gao, Zhiming Wang $(\mathbb{D}$, and Quanshu Zeng $\mathbb{D}$ \\ State Key Laboratory of Petroleum Resources and Prospecting, China University of Petroleum (Beijing), Beijing 102249, China \\ Correspondence should be addressed to Zhiming Wang; wangzhiming_cupb@163.com
}

Received 30 April 2021; Revised 10 May 2021; Accepted 25 June 2021; Published 22 July 2021

Academic Editor: Shengnan Nancy Chen

Copyright (C) 2021 Qingchun Gao et al. This is an open access article distributed under the Creative Commons Attribution License, which permits unrestricted use, distribution, and reproduction in any medium, provided the original work is properly cited.

\begin{abstract}
Oil-water two-phase flow through the complex pipeline, consisting of varying pipes and fittings in series or parallel, is commonly encountered in the petroleum industry. However, the majority of the current study is mainly limited to single constant-radius pipe. In this paper, a unified model of oil-water two-phase flow in the complex pipeline is developed based on the combination of pipe serial-parallel theory, flow pattern transformation criterion, two-fluid model, and homogenous model. A case is present to verify the unified model and compare with CFD results. The results show that the proposed unified model can achieve excellent performance in predicting both the flow distributions and pressure drops of oil-water two-phase flow in the complex pipeline. Compared with CFD results for water volumetric fractions ranging from $0 \%$ to $100 \%$, the highest absolute percentage error of the proposed model is $14.4 \%$ and the average is $9.8 \%$.
\end{abstract}

\section{Introduction}

Oil-water two-phase flow in the complex pipeline, consisting of varying pipes and fittings in series or parallel, is commonly encountered in the petroleum industry $[1,2]$. Study on oil-water two-phase flow law in complex pipeline, especially the diversion, and the pressure drop, can not only solve the important problems in the process of oil production but also has important significance to improve the multiphase flow theory. However, the study is mainly limited to single constant-radius pipe at present $[3,4]$, and the oil-water two-phase flow in complex pipelines still needs further study.

Up to date, research focused on oil-water two-phase flow performance can be categorized by the following three types, encompassing theoretical mathematical model, numerical simulation, and laboratory experiments. Thanks to the rapid advances in computational capacity in recent years, the numerical simulation approach has developed at an impressive speed $[5,6]$. Several physics fully-coupled commercial numerical simulator have been massively utilized for analysis, like CFD and FLUENT [7]. However, it is still challenging to completely mimic oil-water flow behavior inside realistic complex pipelines with the use of numerical simulation. Also, the simulation model requires total re-establishment when the realistic case evolves, which aggravates its complexity $[8,9]$. As for the laboratory experiments, relevant results can be directly examined and collected, which is evidently its advantage. Notably, the accuracy or reliability of the experimental data is heavily dependent on the quality of apparatus and examination method, suffering strong uncertainty [10-12]. In contrast, the mathematical model derived from classic theory not only provides instanton reliable results but also facilitates to identify the effect of each influential factor [13]. Motivated by the above perspective, a theoretical model is proposed in this work and expects to provide a new available option to investigate oil-water flow behavior in complex pipelines. And the numerical simulation is used to clarify the reliability of the proposed model based on regular scenarios.

In this paper, a unified model of oil-water two-phase flow in the complex pipeline is developed based on the combination of pipe serial-parallel theory, flow pattern transformation criterion, two-fluid model, and homogenous model. A case is present to verify the unified model, to compare with CFD results, to analyze the diversion of oil-water mixture 
under different oil viscosity and water content, and to predict the pressure drop.

\section{Model Establishment}

In this paper, four kinds of oil-water stratified flow patterns including o \& w, w/o \& w, w/o \& o/w, and o \& $\mathrm{o} / \mathrm{w}$ were considered $[14,15]$, in which two kinds of oilwater dispersed flow patterns such as w/o and o/w were considered.

The basic assumptions of the model are shown below: oil and water are Newton incompressible fluid; no heat conduction or working phenomenon between fluid and the outside world, the fluid system is under the isothermal flow state; steady flow; the oil-water interface is assumed to be planar; the interaction between the pipeline and pipe fittings is neglectful; the fluid properties in different channels are consistent.

2.1. Flow Regime Transition Criterion. Because the density difference between oil and water is small, and their interfacial tension is low, the oil-water interface is easy to fluctuate and translate into other flow patterns. The transition from stratified flow to dispersed flow depends on the equilibrium relationship between the total turbulent kinetic energy and the total free energy of the dispersed phase. If the turbulent kinetic energy is larger, the dispersed phase will be dispersed in the continuous phase in the form of spherical droplets and collide with each other in the turbulent motion [16, 17]. At the same time, if the droplet size is too large, under the influence of the turbulent force, the droplet will break. Therefore, the maximum dispersion of each flow unit depends on the turbulence intensity of the continuous phase. According to Atmaca et al. [18], when the oil and water mixture velocity is larger than a certain critical value, the fluid will translate the flow pattern from the oil-water two-phase flow to the oil-water two-phase dispersed flow.

$$
v_{m}>\left\{\frac{6.325 C_{e} \varphi_{\text {Int }}\left[\sigma_{o w}\left(\rho_{w}-\rho_{o}\right) g\right]^{1 / 2}}{f_{m} \rho_{m}}\right\}^{1 / 2} .
$$

Among them, $v_{m}$ represents the speed of the mixture, $\mathrm{m} / \mathrm{s} ; C_{e}$ represents coefficient, dimensionless; $\varphi_{\text {Int }}$ is the internal phase volume fraction, dimensionless; $\sigma_{o w}$ is the oil-water surface tension; $\mathrm{N} / \mathrm{m} ; \rho_{w}$ represents water density, $\mathrm{kg} / \mathrm{m}^{3} ; \rho_{\mathrm{o}}$ represents oil density, $\mathrm{kg} / \mathrm{m}^{3} ; g$ is the acceleration of gravity, $\mathrm{m} / \mathrm{s}^{2} ; f_{m}$ represents the friction coefficient between the wall and the mixture, dimensionless; $\rho_{\mathrm{m}}$ represents the density of liquid mixture; $\mathrm{kg} / \mathrm{m}^{3}$.

$$
C_{e}=\frac{2.5-|\sin \theta|}{2},
$$

$$
\begin{aligned}
& \int \frac{64}{\operatorname{Re}_{m}} \quad\left(\operatorname{Re}_{m} \leq 2320\right), \\
& f_{m}= \begin{cases}\frac{\operatorname{Re}_{m}}{1680} & \left(2320<\operatorname{Re}_{m}<4000\right) \\
\frac{0.3164}{\operatorname{Re}_{m}^{0.25}} & \left(4000<\mathrm{Re}<10^{5}\right),\end{cases} \\
& \operatorname{Re}_{m}=\frac{\rho_{m} v_{m} d}{\mu_{m}} \\
& \rho_{m}=\rho_{c}\left(1-\varphi_{\text {Int }}\right)+\rho_{d} \varphi_{\text {Int }}, \\
& v_{m}=v_{c}+v_{d}, \\
& \mu_{m}=\mu_{c}\left(1-\varphi_{\text {Int }}\right)^{-2.5} \eta_{c}>\eta_{c r} \\
& \eta_{c r}=\frac{1}{1+\left(\mu_{o} / \mu_{w}\right)^{0.4}\left(\rho_{o} / \rho_{w}\right)^{0.6}},
\end{aligned}
$$

where $\theta$ represents the angle deviating from the horizontal, degrees; $\mathrm{Re}_{m}$ is the mixture Reynolds number, dimensionless; $d$ is wellbore diameter; $\mathrm{m} ; \mu_{m}$ is the mixed liquid viscosity, $\mathrm{Pa} * s ; \rho_{c}$ represents the continuous phase density, $\mathrm{kg} / \mathrm{m}^{3} ; \rho_{\mathrm{d}}$ represents the dispersion phase density, $\mathrm{kg} / \mathrm{m}^{3}$; $v_{c}$ represents the continuous phase velocity, $\mathrm{m} / \mathrm{s} ; v_{d}$ is dispersion phase velocity, $\mathrm{m} / \mathrm{s} ; \mu_{c}$ is the continuous phase viscosity, $\mathrm{Pa} s ; \eta_{c r}$ represents the critical water content, dimensionless.

2.2. Fluid Flow in the Horizontal Pipe. The control body of the oil-water two-phase flow in the horizontal straight pipe is shown in Figure 1.

A two-phase flow model in the horizontal straight pipe is established based on the homogeneous flow model, and the momentum balance equation of the control body showed in Figure 1 is shown in equation (9).

$$
\begin{gathered}
-\frac{d p}{d x}=\frac{4 \tau_{m}}{D}, \\
\tau_{m}=\frac{1}{8} f_{m} \rho_{m} v_{m}^{2} .
\end{gathered}
$$

Among them, $\tau_{m}$ is the friction stress between mixed fluid and wellbore wall, $\mathrm{Pa}$; $D$ represents the flow area diameter, m. By integrating the formula (9), the general equation of pressure drop of oil and water two-phase flow in the horizontal pipe can be obtained [19].

$$
\Delta p_{p}=\frac{4 \tau_{m}}{D} L
$$

Among them, $L$ is the horizontal straight pipe length, $\mathrm{m}$.

However, when the fluid flows from the dispersed flow to the stratified flow, the separation phenomenon will occur, as a result, the above equation is not applicable. The pressure drop equation needs to be derived based on the two-fluid model. The momentum equations of the w/o layer and the 

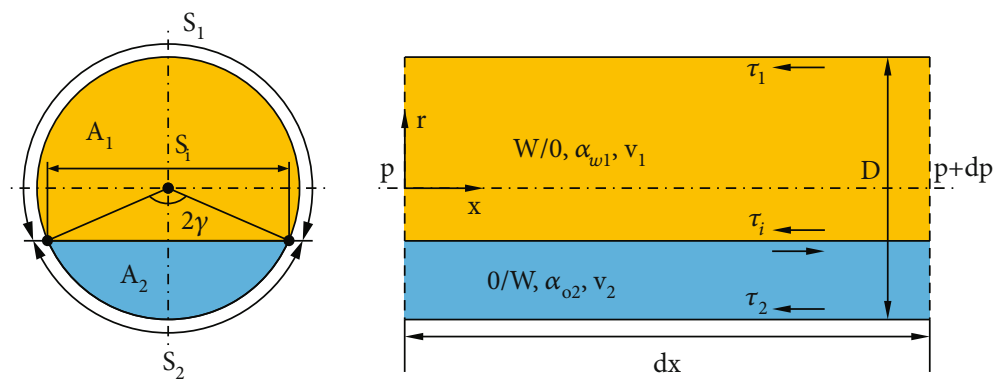

FIgURe 1: Control volume of oil-water two-phase flow in the horizontal pipe.

$\mathrm{o} / \mathrm{w}$ layer column are shown in formulas (12) and (13), respectively.

$$
\begin{aligned}
& -A_{1} \frac{d p}{d x}-\tau_{1} S_{1}-\tau_{i} S_{i}=0 \\
& -A_{2} \frac{d p}{d x}-\tau_{2} S_{2}+\tau_{i} S_{i}=0
\end{aligned}
$$

Among them, $A_{1}$ and $A_{1}$ represent the pipe crosssectional area of w/o layer and o/w layer, respectively, $\mathrm{m}^{2} . P$ is the average pressure in $\mathrm{X}$ section, $\mathrm{Pa} ; \tau_{1}$ and $\tau_{2}$ are the wall friction stress between w/o layer or o/w layer and wellbore, respectively, $\mathrm{Pa} ; S_{1}$ and $S_{2}$ represent the wet week of w/o layer or $\mathrm{o} / \mathrm{w}$ layer, $\mathrm{m} ; \tau_{i}$ is the interface friction stress between w/o layer and o/w layer under oil-water two-phase stratified flow condition, $\mathrm{Pa} ; S_{i}$ is the section chord length for w/o layer and $\mathrm{o} / \mathrm{w}$ layer, $\mathrm{m}$.

Formulas (12) and (13) are added and integrated in order to obtain the general pressure drop equation of the oil-water two-phase stratified flow.

$$
\Delta p_{p}=\frac{\tau_{1} S_{1}+\tau_{2} S_{2}}{A} L
$$

However, several key parameters must be determined for the above model, including the cross-section geometry parameters, the friction stress parameters, and the dispersed phase holdup parameters.

The section geometric parameters include the wetted perimeter and the cross-sectional area of the upper and lower two layers. The wetted perimeter of the upper and lower two layers of the oil-water two-phase flow is shown in formulas (15) and (16), and the cross-sectional area is shown in formulas (17) and (18).

$$
\begin{aligned}
& S_{1}=\pi D-S_{2}, \\
& S_{2}=\gamma D, \\
& A_{1}=\frac{D^{2}}{4}(\pi-\gamma+\sin \gamma \cos \gamma), \\
& A_{2}=\frac{D^{2}}{4}(\gamma-\sin \gamma \cos \gamma) .
\end{aligned}
$$

Among them, $\gamma$ represents the wetter perimeter of the lower $\mathrm{o} / \mathrm{w}$ layer corresponding to the semicircular, dimensionless.

The section chord of w/o layer and o/w layer can be obtained in the same way.

$$
S_{i}=D \sin \gamma
$$

The friction stress is calculated by the concept of friction coefficient.

$$
\begin{aligned}
& \tau_{1}=\frac{1}{8} f_{1} \rho_{1} v_{1}^{2}, \\
& \tau_{2}=\frac{1}{8} f_{2} \rho_{2} v_{2}^{2}, \\
& \rho_{1}=\rho_{o}\left(1-\alpha_{w 1}\right)+\rho_{w} \alpha_{w 1}, \\
& \rho_{2}=\rho_{o} \alpha_{o 2}+\rho_{w}\left(1-\alpha_{o 2}\right) .
\end{aligned}
$$

Among them, $f_{1}$ and $f_{2}$ represent the Moody wall friction coefficient of w/o layer and o/w layer, respectively, dimensionless; $\rho_{1}$ and $\rho_{2}$ represent the effective density of w/o layer and o/w layer, respectively, $\mathrm{kg} / \mathrm{m}^{3} ; v_{1}$ and $v_{2}$ represent the actual flow rate of w/o layer and o/w layer, respectively, $\mathrm{m} / \mathrm{s} ; a_{w 1}$ and $a_{o 2}$ represent the dispersed phase concentration of w/o layer and $\mathrm{o} / \mathrm{w}$ layer, respectively, dimensionless.

The effective Reynolds numbers of the upper and lower two layers of oil-water two-phase flow are shown in formulas (24) and (25), respectively [20, 21].

$$
\begin{aligned}
& \operatorname{Re}_{1}=\frac{\rho_{1} v_{1} d_{1}}{\mu_{1}}, \\
& \operatorname{Re}_{2}=\frac{\rho_{2} v_{2} d_{2}}{\mu_{2}} .
\end{aligned}
$$

Among them, $d_{1}$ and $d_{2}$ represent the hydraulic diameter of w/o layer and o/w layer, respectively, $\mathrm{m} ; \mu_{1}$ and $\mu_{2}$ represent the effective viscosity of w/o layer and o/w layer, respectively, $\mathrm{Pa} *$ s. 


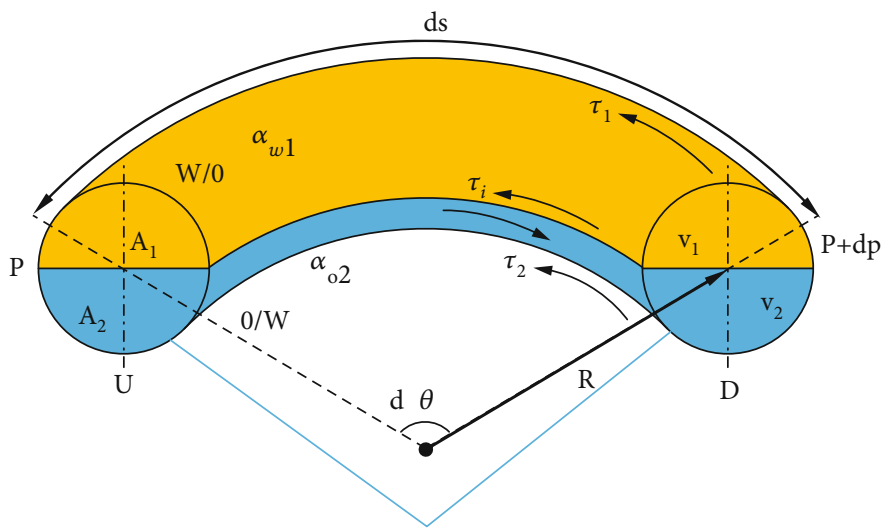

FIgURe 2: Control volume of oil/water two-phase flow in the elbow.

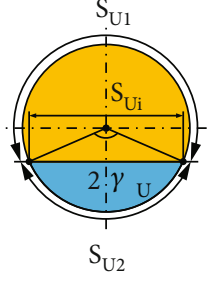

$\mathrm{U}-\mathrm{U}$

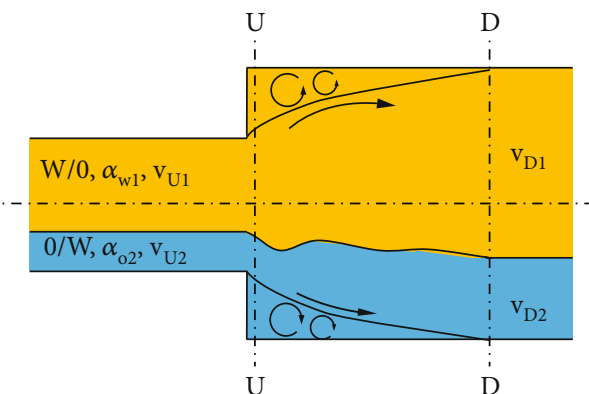

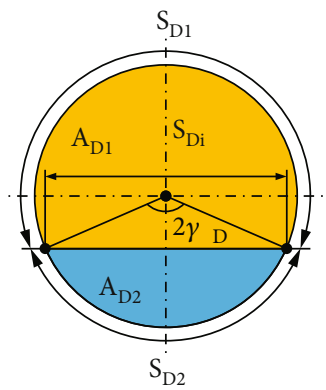

D-D

Figure 3: Control volume of oil-water two-phase flow in the sudden expanded fitting.

According to the velocity of each layer, the hydraulic diameter of w/o layer and o/w layer is different.

$$
\begin{aligned}
& d_{1}= \begin{cases}\frac{4 A_{1}}{S_{1}+S_{2}} & \left(v_{1}>v_{2}\right), \\
\frac{4 A_{1}}{S_{1}} & \left(v_{1} \leq v_{2}\right),\end{cases} \\
& d_{2}= \begin{cases}\frac{4 A_{2}}{S_{2}+S_{i}} & \left(v_{1}<v_{2}\right), \\
\frac{4 A_{2}}{S_{2}} & \left(v_{1} \geq v_{2}\right) .\end{cases}
\end{aligned}
$$

Using Roscoe-Brinkman formula to calculate the effective viscosity of w/o and $\mathrm{o} / \mathrm{w}$ layers.

$$
\begin{aligned}
& \mu_{1}=\mu_{o}\left(1-\alpha_{w 1}\right)^{-2.5}, \\
& \mu_{2}=\mu_{w}\left(1-\alpha_{o 2}\right)^{-2.5} .
\end{aligned}
$$

2.3. Fluid Flow in the Elbow Pipe. The control body of the oilwater two-phase flow is shown in Figure 2.

It is similar to the horizontal oil-water two-phase flow that the general pressure drops equation of oil-water twophase disperse flow and stratified flow in the elbow pipe can be obtained by integrating the pressure gradient equation along the radial direction.

$$
\begin{aligned}
& \Delta p_{e f}=\frac{4 \tau_{m}}{D} R \theta, \\
& \Delta p_{e f}=\left(\tau_{1} S_{1}+\tau_{2} S_{2}\right) \frac{R}{A} \theta,
\end{aligned}
$$

where $R$ is the radius of the elbow pipe, $\mathrm{m} ; \theta$ is the circular measure of the elbow pipe, rad.

2.4. Fluid Flow through the Sudden Expansion Joint. The control body of the oil-water two-phase flow in the sudden expansion joint is shown in Figure 3. The friction stress and gravity are neglected, and it is assumed that there is no mass exchange between the upper and lower two layers.

Based on the homogeneous flow model, a general pressure drop equation for oil-water two-phase flow in the sudden expansion joint is established, as shown in equation (32).

$$
\Delta p_{s e f}=\left(1-\frac{A_{U}}{A_{D}}\right)^{2} \frac{v_{U}^{2}}{2} \rho_{m}
$$

Similarly, the separation phenomenon occurs when the dispersed flow is transferred to the stratified flow, and the above equation is no longer applicable. The momentum equation of oil-water two-phase stratified flow in the sudden 

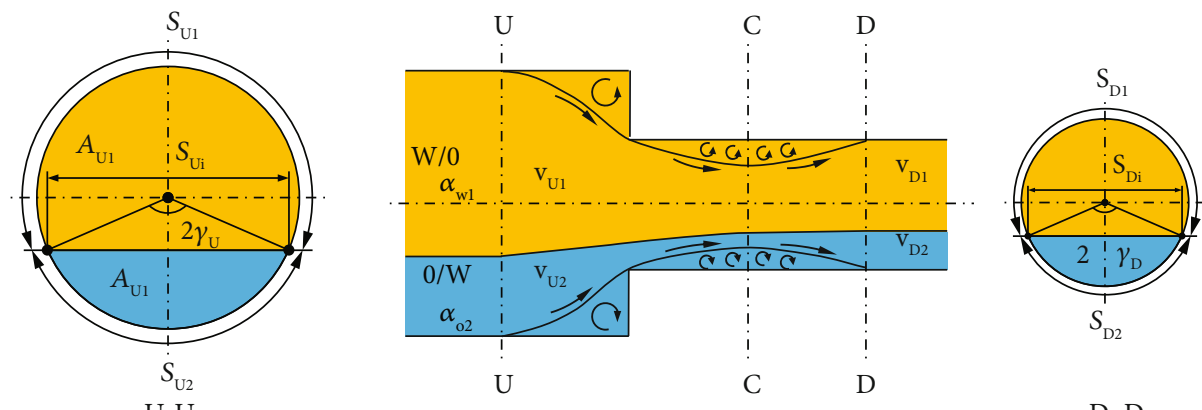

D-D

FIGURE 4: Control volume of oil-water two-phase flow in the sudden shrunken fitting.

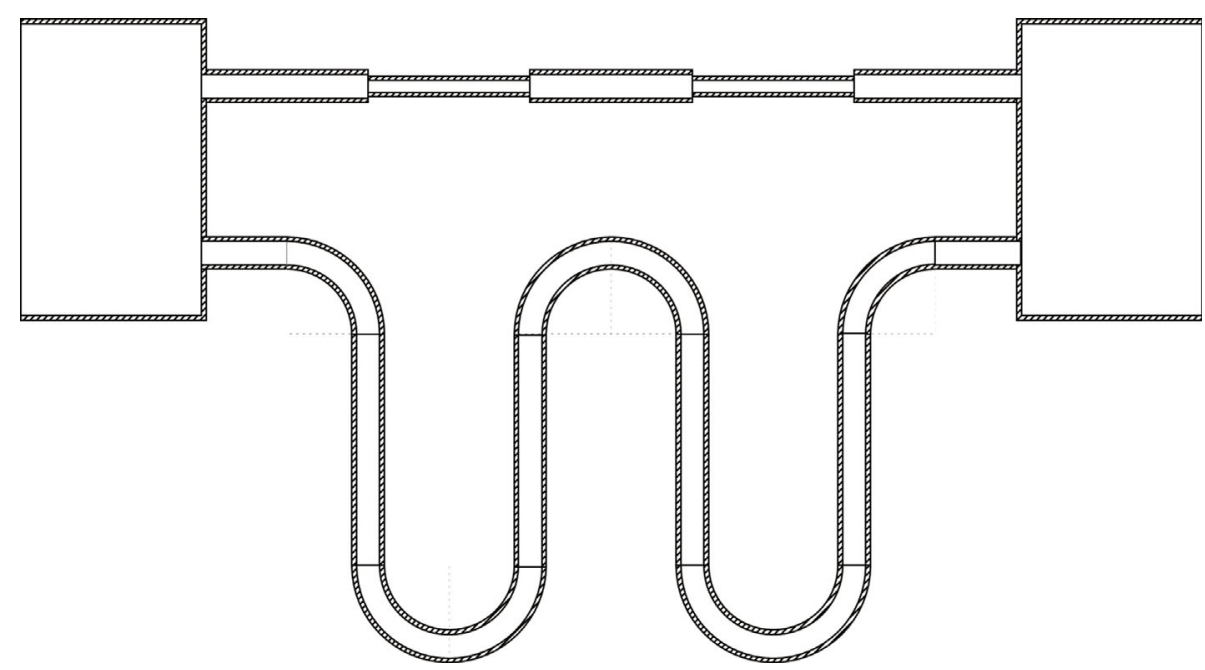

FIGURE 5: Diagram of the complex pipeline.

TABLE 1: Structure parameters for the present complex pipeline.

\begin{tabular}{|c|c|c|c|}
\hline \multicolumn{2}{|c|}{ Structure parameters } & Value & Unit \\
\hline \multirow{6}{*}{ Channel 1} & Sudden shrunken joints number & 1 & Dimensionless \\
\hline & Sudden expansion joints number & 1 & Dimensionless \\
\hline & Expansion channel length & 0.1633 & $\mathrm{~m}$ \\
\hline & Expansion channel radius & 0.005 & $\mathrm{~m}$ \\
\hline & Shrunken channel length & 0.1633 & $\mathrm{~m}$ \\
\hline & Shrunken channel radius & 0.0025 & $\mathrm{~m}$ \\
\hline \multirow{3}{*}{ Channel 2} & Elbow pipe number & 12 & Dimensionless \\
\hline & Bend angle & 90 & $\circ$ \\
\hline & Bending radius & 0.03 & $\mathrm{~m}$ \\
\hline
\end{tabular}

expansion joint can be derived based on the two-fluid model.

$$
p_{U} A_{U}-p_{D} A_{D}+p^{\prime}\left(A_{D}-A_{U}\right)=\rho_{1} q_{1}\left(v_{D 1}-v_{U 1}\right)+\rho_{2} q_{2}\left(v_{D 2}-v_{U 2}\right),
$$

where $q_{1}$ and $q_{2}$ represent the rate of flow of w/o layer and $\mathrm{o} / \mathrm{w}$ layer, respectively.

$$
q_{1}=A_{U 1} v_{U 1}=A_{D 1} v_{D 1}
$$

$$
q_{2}=A_{U 2} v_{U 2}=A_{D 2} v_{D 2}
$$

According to Che and Li's research [22], the pressure of the $U-U$ cross-section is equal to the pressure of the smaller cross-section before the sudden expansion joint. Take this equal relation into consideration, the general pressure drop equation of oil-water two-phase flow in the sudden expansion joint is obtained.

$$
\Delta p_{s e f}=\frac{\left[\rho_{1} q_{1}\left(v_{D 1}-v_{U 1}\right)+\rho_{2} q_{2}\left(v_{D 2}-v_{U 2}\right)\right]}{A_{D}} .
$$



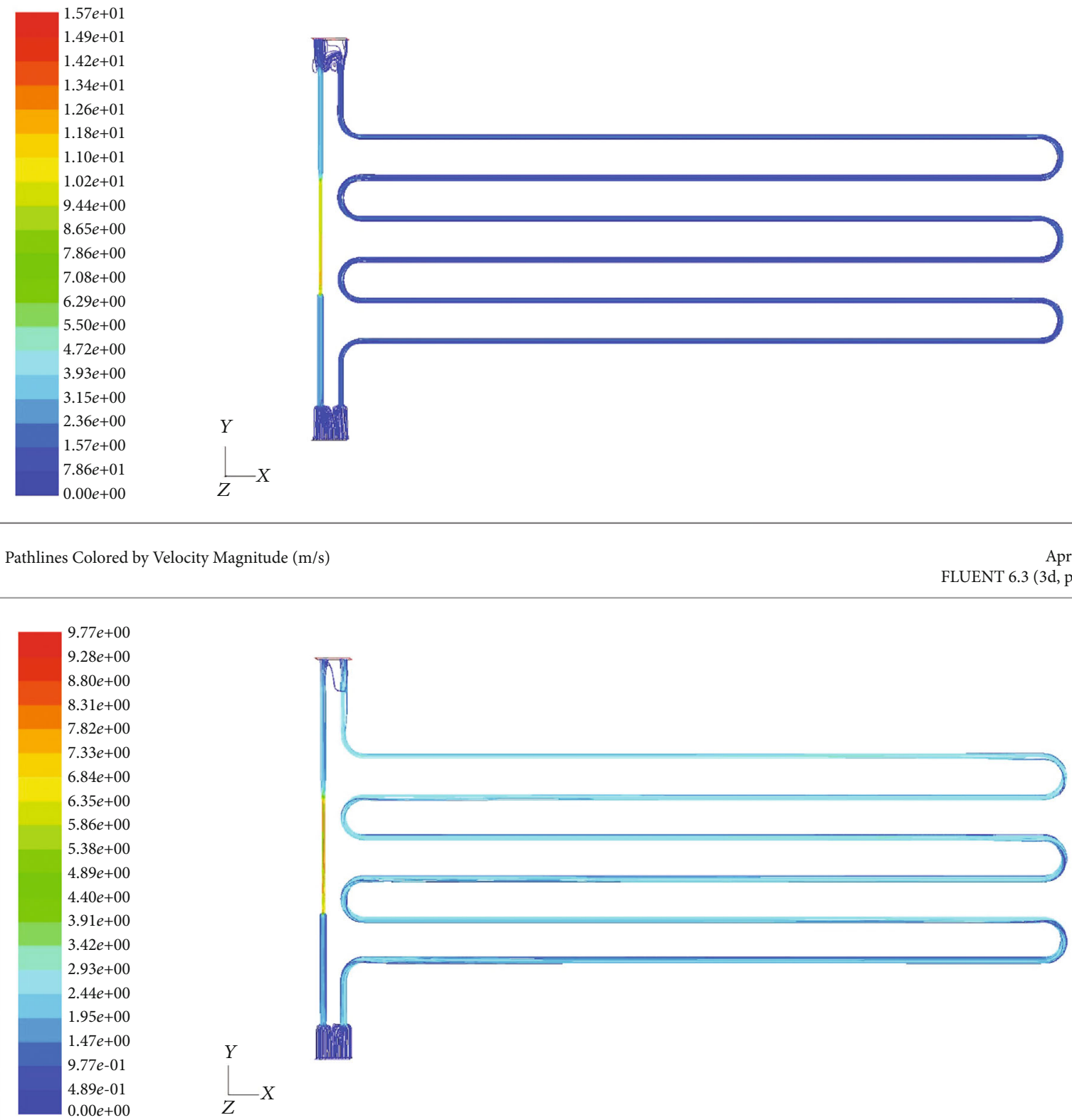

Pathlines Colored by Velocity Magnitude ( $\mathrm{m} / \mathrm{s})$

FIGURE 6: Path line colored by velocity magnitude.

2.5. Fluid Flow through the Sudden Shrunken Joint. The control body of the oil-water two-phase flow in the sudden shrunken joint is shown in Figure 4. The friction stress and gravity are neglected, and it is assumed that there is no mass exchange between the upper and lower two layers.

When the fluid flows into the U-U section and flows out from the $\mathrm{C}-\mathrm{C}$ section, the fluid accelerates and the pressure energy is converted to kinetic energy, in this process, the friction dissipation is small and even little. After the fluid flows through the contraction C-C section, the flow state is similar to that of the sudden expansion joint and is accompanied by friction dissipation. Based on the homogeneous flow model, the general pressure drop equation of oil-water two-phase flow in the sudden shrunken joint can be established, as shown in equation (37).

$$
\begin{aligned}
\Delta p_{s s f} & =\left(1+\frac{1}{C_{v}^{2} C_{c}^{2}}-\frac{2}{C_{c}}\right) \frac{v_{D}^{2}}{2} \rho_{m}, \\
C_{c} & =\frac{A_{C}}{A_{D}},
\end{aligned}
$$




$$
C_{v}=\frac{\bar{v}_{c}}{\bar{v}} .
$$

Among them, $C_{c}$ represent the contraction coefficient, dimensionless; $C_{v}$ represent the velocity coefficient, dimensionless; $\bar{v}_{c}$ is the actual average flow velocity in the contraction section, $\mathrm{m} / \mathrm{s} ; \bar{v}$ is the average velocity in the contraction section, $\mathrm{m} / \mathrm{s}$.

Based on the two-fluid model, the momentum equation of the oil-water two-phase flow is

$$
p_{C} A_{C}-p_{D} A_{D}+p^{\prime}\left(A_{D}-A_{C}\right)=\rho_{1} q_{1}\left(v_{D 1}-v_{C 1}\right)+\rho_{2} q_{2}\left(v_{D 2}-v_{C 2}\right),
$$

where

$$
\begin{aligned}
& q_{1}=A_{U 1} v_{U 1}=A_{C 1} v_{C 1}=A_{D 1} v_{D 1}, \\
& q_{2}=A_{U 2} v_{U 2}=A_{C 2} v_{C 2}=A_{D 2} v_{D 2} .
\end{aligned}
$$

Similarly, the pressure of the C-C section is equal to the pressure at the outlet whose cross-section is larger than others of the former sudden shrunken joint, then substitute into the formula (40), recognize the formula then obtain the general pressure drop equation for oil-water two-phase stratified flow.

$$
\Delta p_{s s f}=\frac{\left[\rho_{1} q_{1}\left(v_{D 1}-v_{C 1}\right)+\rho_{2} q_{2}\left(v_{D 2}-v_{C 2}\right)\right]}{A_{D}} .
$$

2.6. Serial-Parallel Pipe Theory. There are two important rules when the straight pipe is connected with various pipe fittings in series [23-25]:

$$
\begin{gathered}
Q=Q_{1}=Q_{2}=\cdots=Q_{n}, \\
\Delta P=\Delta P_{1}+\Delta P_{2}+\cdots+\Delta P_{n} .
\end{gathered}
$$
allel:

These two rules change when they are connected in par-

$$
\begin{gathered}
Q=Q_{1}+Q_{2}+\cdots+Q_{n}, \\
\Delta P=\Delta P_{1}=\Delta P_{2}=\cdots=\Delta P_{n} .
\end{gathered}
$$

Therefore, by means of simultaneous (44)-(47), the splitflow and pressure drop of oil-water two-phase flow can be obtained.

\section{Case Study}

Figure 5 is the schematic diagram of the complex pipeline, which contains 2 parallel channels, each of which is made up of a series of pipes and fittings, which includes the common fittings and connections in the petroleum industry. The model is verified by the example, and the results are compared with the numerical simulation results.

The structure parameters of the complex pipeline are shown in Table 1, which is generated in the professional CAD software SOLIDWORKS, transferred to the GAMBIT
TABLE 2: Fluid parameters for oil-water two-phase flow in the complex pipeline.

\begin{tabular}{lcc}
\hline Fluid parameters & Value & $\mathrm{Unit}$ \\
\hline Rate of flow & 30 & $\mathrm{~m}^{3} / \mathrm{D}$ \\
Water content & $0,10,20,30,40,50,60,70,80,90,100$ & $\%$ \\
\hline Oil phase & & \\
Density & 850 & $\mathrm{~kg} / \mathrm{m} 3$ \\
$\quad$ Viscosity & $1,10,100$ & $\mathrm{mPa} \cdot \mathrm{s}$ \\
Water phase & & \\
Density & 998.2 & $\mathrm{~kg} / \mathrm{m}^{3}$ \\
Viscosity & 1.003 & $\mathrm{mPa} \cdot \mathrm{s}$ \\
\hline
\end{tabular}

software in the FLUENT through the CAD interface, then through Boolean operation get the internal flow model and mesh division. When using the FLUENT software to calculate, the inlet is set as the velocity inlet (velocity-inlet) condition, the exit is set as the outflow (outflow) condition, and the other is the default (wall) condition. The laminar flow and turbulent flow are simulated by the laminar flow model and the standard $\kappa-\varepsilon$ model, respectively. The mixed model and VOF model are used to simulate the oil-water twophase dispersion and stratified flow, respectively. And the inlet flow rate is set as $30 \mathrm{~m}^{3} / \mathrm{D}$, and the velocity streamline diagram of oil phase and water phase through the complex pipeline can be obtained, as shown in Figure 6 .

According to Figure 6, it can be seen that the oil phase and water phase through the complex pipe after shunting vary greatly, this is due to the fact that the pressure drop compositions of the two parallel lines are different, line 1 is mainly of local resistance and has large water resistance; the main pressure drop of line 2 is friction, so its resistance to the oil phase is greater. At the same time, as the great property difference of oil-water mixture in different oil phase viscosity and water content, in order to accurately describe the influence of water cut and oil phase viscosity on distributary situation and pressure drop, moisture content (\%) values are as follows: $0,10,20,30,40,50,60,70,80,90$, and 100 ; the values of the oil-phase viscosity $(\mathrm{cP})$ are as follows: 1,10 , 100 , and other parameters are shown in Table 2.

Substituted the above parameters into the model and the numerical simulation, then the distributary situation and the pressure drop of oil-water two-phase flow through the complex pipeline can be obtained, as shown in Figures 7 and 8 .

According to Figures 7 and 8, the results show that the model is in good agreement with the numerical simulation results. The highest average absolute error is about $14.4 \%$, and the average error is $9.8 \%$ when the oil-water two-phase volumetric water content is $0 \%$ and $100 \%$, respectively. And these curves have 3 major turning point: the first is reverse point, if the oil viscosity increases, the critical volume water content will decrease, then the position of reverse point will move forward; the second one and the 3rd are the turning point making the fluid flow from laminar transition to turbulent transition zone and from turbulent transition zone to the turbulent zone. In addition, if the flow rate is greater than a certain critical value, the flow pattern will also change, which 


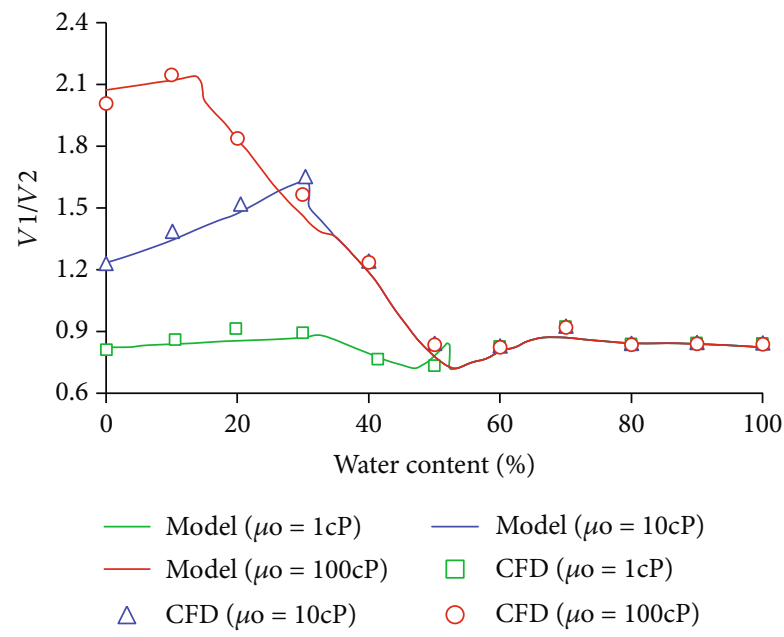

FIGURE 7: Flow distribution through the complex pipeline with varying fluid properties.

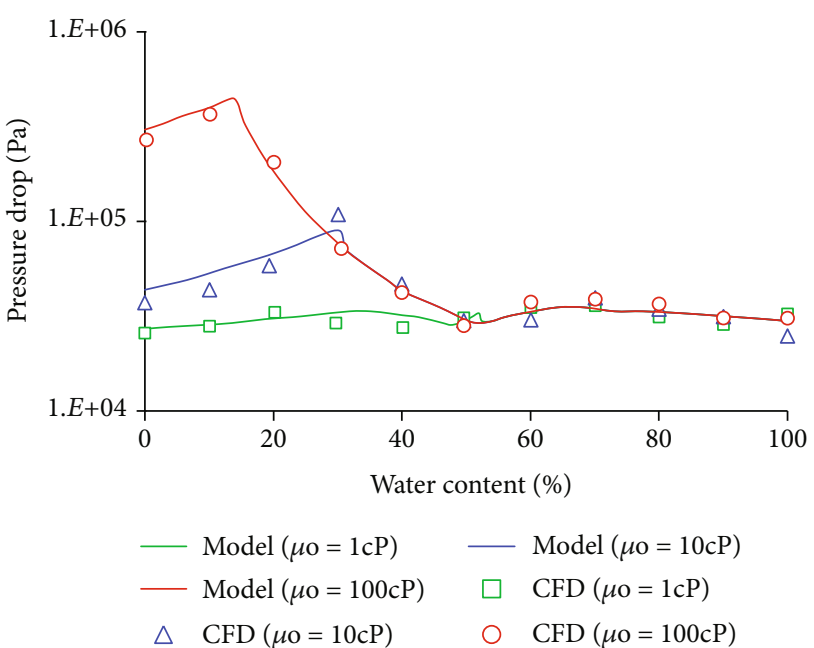

FIGURE 8: Pressure drop through the complex pipeline with varying fluid properties.

will affect the flow distribution. In addition, if the flow rate is greater than a certain critical value, the flow pattern will also change, which will affect the flow distribution.

Therefore, if the mixed liquid water content is larger than the critical moisture content, because the water phase is dominant, the distributary and the pressure drop are basically same under different oil-phase viscosity; in other cases, as the oil phase dominates, the distributary and the pressure drop vary greatly. With the increase of the oil-phase viscosity, the diversion effect will be better. With the increase of water content, the diversion effect will become good at first then go bad, and it will reach the best result at the critical moisture content. Correspondingly, the pressure drops of the oilwater two-phase fluid passing through the device increases with the oil phase-viscosity; with the increasing of water cut, the pressure drops become good at first then go bad and reach the best result at the critical moisture content.

In addition, the close relationship between oil/water two phase flow inside pipelines and huge economic interests from the development of conventional or unconventional geological hydrocarbon should be highlighted, which is an indispensable branch of economic geology. Notably, the inherent scientific question required to be addressed regarding the production of geological hydrocarbon is the multiphase flow inside pipeline. The accurate prediction of flux or pressure field not only relies on the theoretical multiphase flow model but also heavily dependent on surrounding geological condition. In the other words, the research content lays the solid theoretical background for efficient production and tightly ties with economical geology. Also, from the academic perspective, the research content can be regarded as the crossregion between mechanical engineering as well as petroleum engineering. Meanwhile, based on the application motivation, the majority of potential readership will come from petroleum engineering. As a result, the paper content is demonstrated to be closely linked to economic geology, rather than mechanical engineering.

\section{Conclusions}

Based on the theory of series-parallel pipeline, the flow regime transition criterion, two-fluid model, and homogeneous flow model, the unified mechanism model of oilwater two-phase flow through the complex pipeline is established, the model was validated through an example, then compared with numerical simulations, and the main conclusions are as follows:

(1) The model has a performance in predicting the distributary situation and pressure drop of the oilwater two-phase mixture through complex pipeline, the highest average absolute error is about $14.4 \%$, and the average error is $9.8 \%$ when the oil-water two-phase volumetric water content is $0 \%$ and $100 \%$, respectively

(2) The shunt situation of the oil-water two-phase mixture through the complex pipeline will have 3 transitions, due to the transition of antiphase phenomena, 
the transition from laminar flow zone to the turbulent transition zone, and the transition from the transition zone to the turbulent flow zone. With the increase of water content, the diversion effect will become good at first then go bad, and it will reach the best result at the critical moisture content

(3) Corresponding to the diversion situation, the pressure drop of oil-water mixture fluid through the example device will also have 3 transitions, and with the increasing of water cut, the pressure drop become good at first then go bad and reach the best result at the critical moisture content

\section{Data Availability}

Data will be available under request.

\section{Conflicts of Interest}

The authors declare that they have no conflicts of interest.

\section{References}

[1] Z. M. Wang, J. N. Xiao, J. G. Wei, X. Q. Wang, and W. J. Shi, "Study on pressure drop of oil-water vary mass dispersed flow in horizontal wellbore," Chinese Journal of Hydrodynamics, Ser. A, vol. 26, no. 3, pp. 284-288, 2011.

[2] X. Lu, B. Cao, K. Xie et al., "Enhanced oil recovery mechanisms of polymer flooding in a heterogeneous oil reservoir," Petroleum Exploration and Development, vol. 48, no. 1, pp. 169178, 2021.

[3] D. Biberg and G. Halvorsen, "Wall and interfacial shear stress in pressure driven two-phase laminar stratified pipe flow," International Journal of Multiphase Flow, vol. 26, no. 10, pp. 1645-1673, 2000.

[4] S. T. Johansen, S. Mo, E. Meese, J. E. S. Oliveira, J. F. R. Reyes, and J. N. E. Carneiro, CFD Simulations of Multiphase Flows Containing Large Scale Interfaces and Dispersed Phases with Selected Production Technology Applications, In OTC Brasil, Offshore Technology Conference, 2015.

[5] W. Fu, Z. Wang, J. Zhang, Y. Cao, and B. Sun, "Investigation of rheological properties of methane hydrate slurry with carboxmethylcellulose," Journal of Petroleum Science and Engineering, vol. 184, p. 106504, 2020.

[6] N. J. Alqahtani, T. Chung, Y. D. Wang, R. T. Armstrong, P. Swietojanski, and P. Mostaghimi, "Flow-based characterization of digital rock images using deep learning," SPE Journal, pp. 1-12, 2021.

[7] J. Shi, M. Gourma, and H. Yeung, "A CFD study on horizontal oil-water flow with high viscosity ratio," Chemical Engineering Science, vol. 229, p. 116097, 2021.

[8] A. Riaz and H. A. Tchelepi, "Numerical simulation of immiscible two-phase flow in porous media," Physics of Fluids, vol. 18, no. 1, article 014104, 2006.

[9] A. H. Kohanpur, M. Rahromostaqim, A. J. Valocchi, and M. Sahimi, "Two-phase flow of $\mathrm{CO}_{2}$-brine in a heterogeneous sandstone: characterization of the rock and comparison of the lattice- Boltzmann, pore-network, and direct numerical simulation methods," Advances in Water Resources, vol. 135, p. $103469,2020$.
[10] N. Philippe, H. Davarzani, S. Colombano, M. Dierick, P. Y. Klein, and M. Marcoux, "Experimental study of the temperature effect on two-phase flow properties in highly permeable porous media: application to the remediation of dense nonaqueous phase liquids (DNAPLs) in polluted soil," Advances in Water Resources, vol. 146, p. 103783, 2020.

[11] Y. Wu, L. Cheng, L. Ma et al., "A transient two-phase flow model for production prediction of tight gas wells with fracturing fluid-induced formation damage," Journal of Petroleum Science and Engineering, vol. 199, p. 108351, 2021.

[12] W. Fu, Z. Wang, J. Zhang, and B. Sun, "Methane hydrate formation in a water-continuous vertical flow loop with xanthan gum," Fuel, vol. 265, p. 116963, 2020.

[13] E. Khamehchi, M. Zolfagharroshan, and M. R. Mahdiani, “A robust method for estimating the two-phase flow rate of oil and gas using wellhead data," Journal of Petroleum Exploration and Production Technology, vol. 10, no. 6, pp. 2335-2347, 2020.

[14] S. K. Dewangan, S. K. Senapati, and V. Deshmukh, "CFD investigation of parameters affecting oil-water stratified flow in a channel," International Journal of Mathematical, Engineering and Management Sciences, vol. 5, no. 4, pp. 602-613, 2020.

[15] S. A. Ahmed and B. John, "Dimensionless parameters to identify transition from stratified to non-stratified flow pattern in liquid-liquid horizontal pipe flow," Flow, Turbulence and Combustion, pp. 1-29, 2021.

[16] Z. Sun, X. Li, W. Liu, T. Zhang, M. He, and H. Nasrabadi, "Molecular dynamics of methane flow behavior through realistic organic nanopores under geologic shale condition: pore size and kerogen types," Chemical Engineering Journal, vol. 398, p. 124341, 2020.

[17] K. Mydlarz-Gabryk, M. Pietrzak, and L. Troniewski, "Study on oil-water two-phase upflow in vertical pipes," Journal of Petroleum Science and Engineering, vol. 117, pp. 28-36, 2014.

[18] S. Atmaca, C. Sarica, H. Q. Zhang, and A. S. al-Sarkhi, "Characterization of oil/water flows in inclined pipes," SPE Projects, Facilities \& Construction, vol. 4, no. 2, pp. 41-46, 2009.

[19] Z. M. Wang, The Completion Optimization Theory and Application of Complex Well, Petroleum Industry Press, Beijing, 2010.

[20] J. L. Chen and T. P. Chen, Gas-Liquid Two-Phase Pipe Flow $[M]$, Petroleum Industry Press, Beijing, 2010.

[21] X. Chen and K. R. Sreenivasan, "Reynolds number scaling of the peak turbulence intensity in wall flows," Journal of Fluid Mechanics, vol. 908, 2021.

[22] D. F. Che and H. X. Li, Multiphase Flow and Its Application, Xi'an Jiaotong University Press, Xi'an, 2007.

[23] Z. Sun, J. Shi, K. Wu, T. Zhang, D. Feng, and X. Li, "Effect of pressure-propagation behavior on production performance: implication for advancing low-permeability coalbed-methane recovery," SPE Journal, vol. 24, no. 2, pp. 681-697, 2019.

[24] Y. Wu, L. Cheng, J. Killough et al., "Integrated characterization of the fracture network in fractured shale gas Reservoirs-stochastic fracture modeling, simulation and assisted history matching," Journal of Petroleum Science and Engineering, vol. 205, p. 108886, 2021.

[25] R. Xiao, Q. Hu, and J. Li, “A model-based health indicator for leak detection in gas pipeline systems," Measurement, vol. 171, p. 108843, 2021. 